OPEN ACCESS

Edited by:

Chaminda Jayampath Seneviratne, National Dental Centre of

Singapore, Singapore

Reviewed by:

Lucia Elena Alvarado-Arnez,

Franz Tamayo University, Bolivia Lichao Ge,

First Affiliated Hospital of Wenzhou

Medical University, China

*Correspondence:

Maoming Xiong

ayfyxmm@163.com

tThese authors have contributed equal to this work

Specialty section:

This article was submitted to Infectious Diseases-Surveillance,

Prevention and Treatment,

a section of the journal

Frontiers in Public Health

Received: 12 May 2020 Accepted: 27 November 2020 Published: 14 January 2021

Citation:

He $X$, Cheng $X$, Feng $X$, Wan $H$, Chen $S$ and Xiong M (2021) Clinical Symptom Differences Between Mild and Severe COVID-19 Patients in China: A Meta-Analysis.

Front. Public Health 8:561264. doi: 10.3389/fpubh.2020.561264

\section{Clinical Symptom Differences Between Mild and Severe COVID-19 Patients in China: A Meta-Analysis}

\author{
Xiaobo $\mathrm{He}^{1+}$, Xiao Cheng ${ }^{2 \dagger}$, Xudong Feng ${ }^{3+}$, Hong Wan ${ }^{1+}$, Sihan Chen ${ }^{1}$ and \\ Maoming Xiong ${ }^{1 *}$ \\ ${ }^{1}$ Department of General Surgery, The First Affiliated Hospital of Anhui Medical University, Hefei, China, ${ }^{2}$ Department of \\ Pathology, Anhui Medical University, Hefei, China, ${ }^{3}$ Zhejiang University, Hangzhou, China
}

Objective: The prognosis of mild and severe patients has prominent differences during the prevalence of COVID-19, and it will be significant to identify patients' potential risk of progressing to severe cases according to their first clinical presentations. Therefore, we aim to review the clinical symptoms of the COVID-19 epidemic systematically.

Methods: We searched PubMed, Embase, Web of Science, and CNKI (Chinese Database) for studies about the clinical features of COVID-19 in China from March 18 to April 18. Then we used REVMAN to conduct a meta-analysis.

Results: After screening, 20 articles including 3,326 COVID-19 confirmed cases were selected from 142 articles we retrieved at the beginning of our research. We divided all the cases into a severe group (including severe and critically severe patients) and a mild group according to the "Diagnosis and Treatment Protocol for Novel Coronavirus InfectionInduced Pneumonia" version 4 (trial). Of all the initial symptoms (including fever, cough, abdominal pain, anorexia, chest tightness, diarrhea, dyspnea, expectoration, fatigue, headache, hemoptysis, myalgia, nausea or vomiting, and pharyngalgia) we studied, we found that cough (odds ratio $[\mathrm{OR}]=1.4,95 \%$ confidence interval $[\mathrm{Cl}]: 1.2-1.7 ; p<$ $0.001)$, fever (OR $=1.5,95 \% \mathrm{Cl}: 1.2-1.9 ; p<0.001)$, dyspnea $(\mathrm{OR}=6.2,95 \% \mathrm{Cl}$ : 3.6-10.6; $p<0.001)$, diarrhea (OR $=2.6,95 \% \mathrm{Cl}: 1.3-4.9 ; p<0.001)$, fatigue (OR $=2.1,95 \% \mathrm{Cl}: 1.3-3.3 ; p<0.01)$, expectoration (OR $=1.7,95 \% \mathrm{Cl}: 1.2-2.6 ; p<$ $0.01)$, myalgia $(\mathrm{OR}=1.6,95 \% \mathrm{Cl}: 0.8-3.1 ; p<0.001)$, hemoptysis $(\mathrm{OR}=4.0,95 \%$ Cl: $1.5-11.3 ; p<0.001$ ), abdominal pain ( $\mathrm{OR}=7.5$, 95\% Cl: 2.4-23.4; $p<0.001)$, and anorexia $(\mathrm{OR}=2.8,95 \% \mathrm{Cl}: 1.5-5.1 ; p<0.001)$ had a different distribution in two groups and were statistically significant $(p<0.05)$.

Conclusion: COVID-19 patients whose initial manifestation is dyspnea, hemoptysis, anorexia, diarrhea, or fatigue, especially abdominal pain should be closely monitored to prevent disease deterioration.

Keywords: COVID-19, clinical features, differences, risk factor, meta-analysis 


\section{INTRODUCTION}

An outbreak of a novel coronavirus-induced pneumonia occurred in Wuhan in December 2019, with the characteristics of being occult and infectious, with an incubation period of 3-7 days, usually no more than 14 days (1). On February 11, 2020, the World Health Organization (WHO) officially named the epidemic disease caused by the new coronavirus as coronavirus 2019 (coronavirus disease 2019) or COVID-19 (2). According to a study, COVID-19 can be transmitted between humans, and it has a significantly high RO (basic reproduction number, an essential index to evaluate the ability of a virus to spread), which was 3.77 times higher than that of MERS-CoV (3). An official report announced that the virus might have the feature of aerosol transmission. The virus can infect a human in a relatively closed space exposed to a high concentration of aerosols for a long time $(4,5)$. In the early stage of COVID19, major symptoms were fever, dry cough, fatigue, and then breath difficulties, and severe cases can deteriorate to acute respiratory distress syndrome (ARDS) or septic shock, even death. On April 20, 2020, cumulative confirmed cases have reached 84,278 in China according to a report of WHO (6).

It is now universally acknowledged that severe COVID-19 cases have higher mortality than mild cases because severe cases are more likely to suffer ARDS, septic shock, or metabolic acidosis (7). So it is necessary to distinguish between severe and mild patients at an early stage. According to a report by Yong Gao (8), the levels of IL-6 and D-dimer can be measured to estimate the severity of COVID-19 and help to diagnose severe COVID-19 patients earlier. Also, Fei Zhou et al. (9) found that risk factors for death of adult patients with COVID-19 were a higher Sequential Organ Failure Assessment score, older age, and elevated d-dimer at admission. However, for countries or regions with poor health conditions, these methods may not be applicable. Our research aims to distinguish between severe and mild cases with COVID-19 at an early stage by analyzing initial clinical symptoms at admission, so it is easier to manipulate. We focused on 14 initial clinical presentations that most commonly occurred in COVID-19 patients and tried to determine the differences between mild and severe COVID-19 patients. It may help enable the implementation of effective interventions and likely lower the mortality of COVID-19 patients.

At present, over 200 countries are involved in this epidemic, and pneumonia induced by COVID-19 has become an enormous threat to global public health. Many cases emerged inside and outside China over the past month $(2,10-13)$. Although there have been many studies on clinical case analysis, the limited number of cases in each study may lead to different results and more significant bias. Therefore, our study involved over 3,000 confirmed cases to reveal the clinical symptoms of COVID-19 patients and provide help for clinical prevention and control of the epidemic disease.

\begin{tabular}{|c|c|c|c|c|c|c|c|c|c|c|c|c|c|}
\hline Dong L. & 2 & 2 & 2 & 2 & 2 & 1 & 1 & 0 & 2 & 2 & 2 & 2 & 20 \\
\hline Fang $X$. & 2 & 2 & 2 & 2 & 2 & 0 & 0 & 0 & 2 & 2 & 2 & 2 & 18 \\
\hline Guan W. & 2 & 2 & 2 & 2 & 2 & 0 & 1 & 0 & 2 & 2 & 2 & 2 & 19 \\
\hline Li D. & 2 & 2 & 2 & 2 & 2 & 1 & 1 & 0 & 2 & 2 & 2 & 2 & 20 \\
\hline Li K. & 2 & 2 & 2 & 2 & 2 & 1 & 2 & 0 & 2 & 2 & 2 & 2 & 21 \\
\hline Li Y. & 2 & 2 & 2 & 2 & 2 & 1 & 1 & 0 & 2 & 2 & 2 & 2 & 20 \\
\hline Liu K. & 2 & 2 & 2 & 2 & 2 & 1 & 2 & 0 & 2 & 2 & 2 & 2 & 21 \\
\hline Liu W. & 2 & 2 & 2 & 2 & 2 & 0 & 2 & 0 & 2 & 2 & 2 & 2 & 20 \\
\hline Wu C. & 2 & 2 & 2 & 2 & 2 & 1 & 1 & 0 & 2 & 2 & 2 & 2 & 20 \\
\hline Xiang T. & 2 & 2 & 2 & 2 & 2 & 1 & 0 & 0 & 2 & 2 & 2 & 2 & 19 \\
\hline Yuan J. & 2 & 2 & 2 & 2 & 2 & 1 & 1 & 0 & 2 & 2 & 2 & 2 & 20 \\
\hline Zhang J. & 2 & 2 & 2 & 2 & 2 & 0 & 1 & 0 & 2 & 2 & 2 & 2 & 19 \\
\hline Zhang W. & 2 & 2 & 2 & 2 & 2 & 1 & 2 & 0 & 2 & 2 & 2 & 2 & 21 \\
\hline Zheng F. & 2 & 2 & 2 & 2 & 2 & 0 & 2 & 0 & 2 & 2 & 2 & 2 & 20 \\
\hline
\end{tabular}

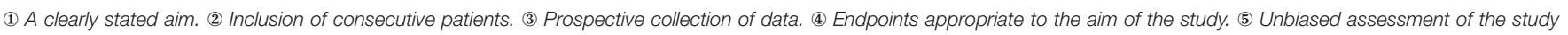

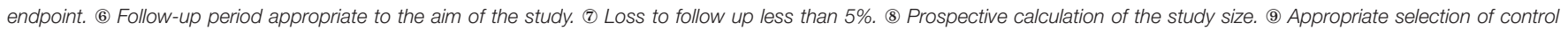
group. (10) Synchronization of control group. (1) Baseline comparable between groups. (12) Appropriately statistical analysis. The global ideal score being 24 for comparative studies. 


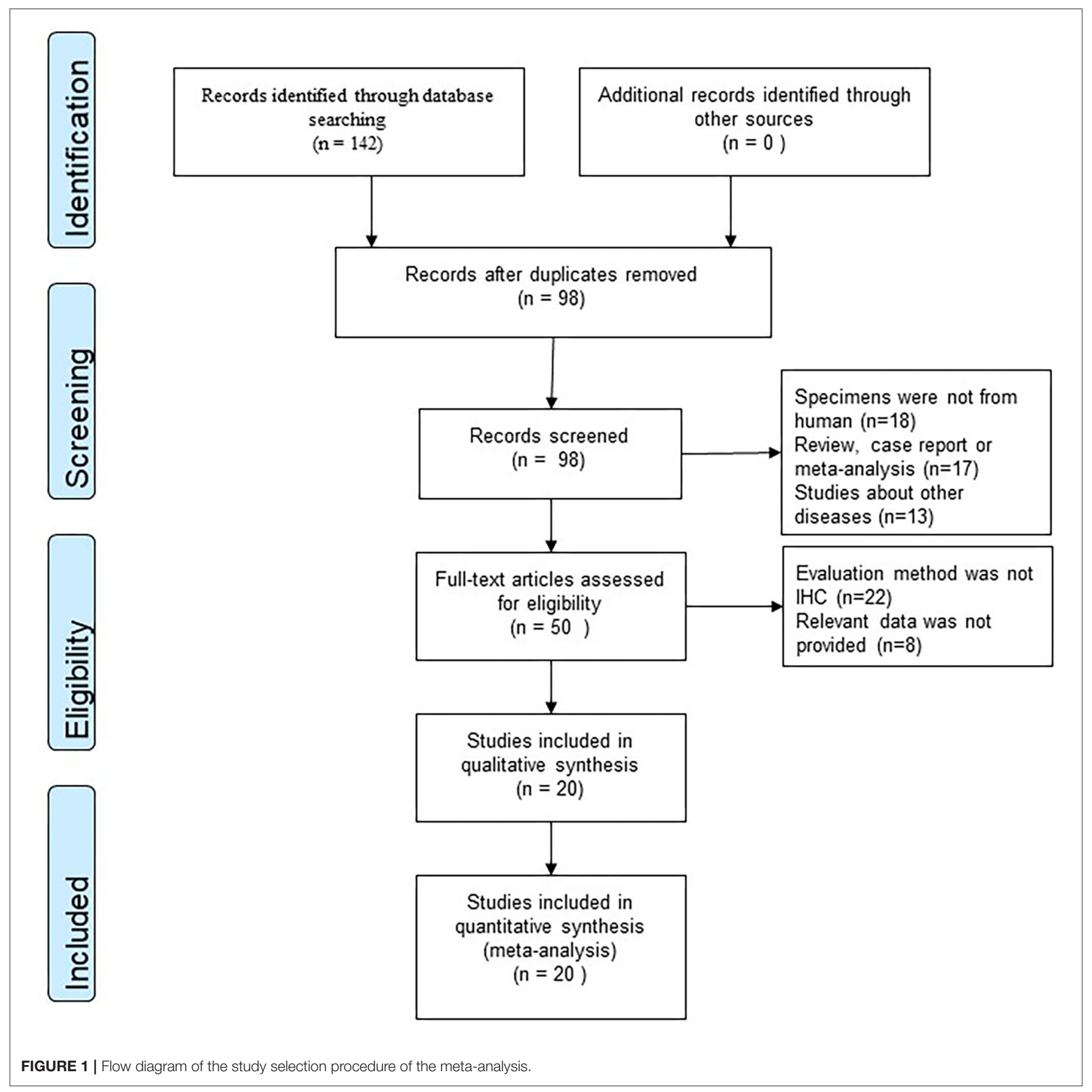

\section{METHODS}

\section{Search Strategy and Inclusion Criteria}

We retrieved four databases, PubMed (https://pubmed.ncbi.nlm. nih.gov/), Embase (https://www.embase.com/), Web of Science (http://isiknowledge.com/), and CNKI (https://www.cnki.net/), to acquire case analysis studies on coronavirus disease 2019. Articles published between March 18, 2020, and April 18, 2020 were included. The search terms we used were as follows:
("SARS-CoV-2" or "nCoV" or "COVID-19," or "coronavirus") AND ("clinical feature" or "clinical characteristic" or "clinical symptom"). We evaluated all the search results according to the Preferred Reporting Items for Systematic Reviews and Meta-Analyses (PRISMA) statement. Original articles related to COVID-19 patients in China without restriction on study design or study type were included. Studies on pregnant and infant patients, without reliable clinical data, and outside China were excluded. 


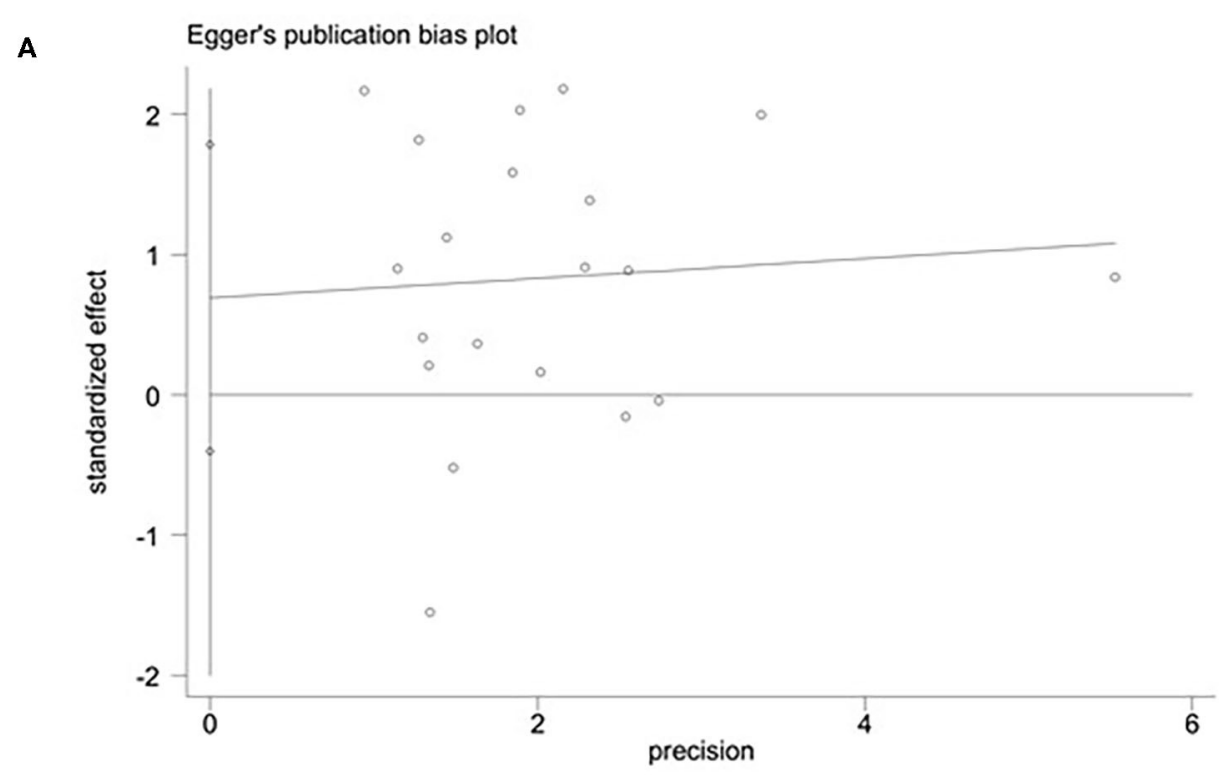

\section{B}

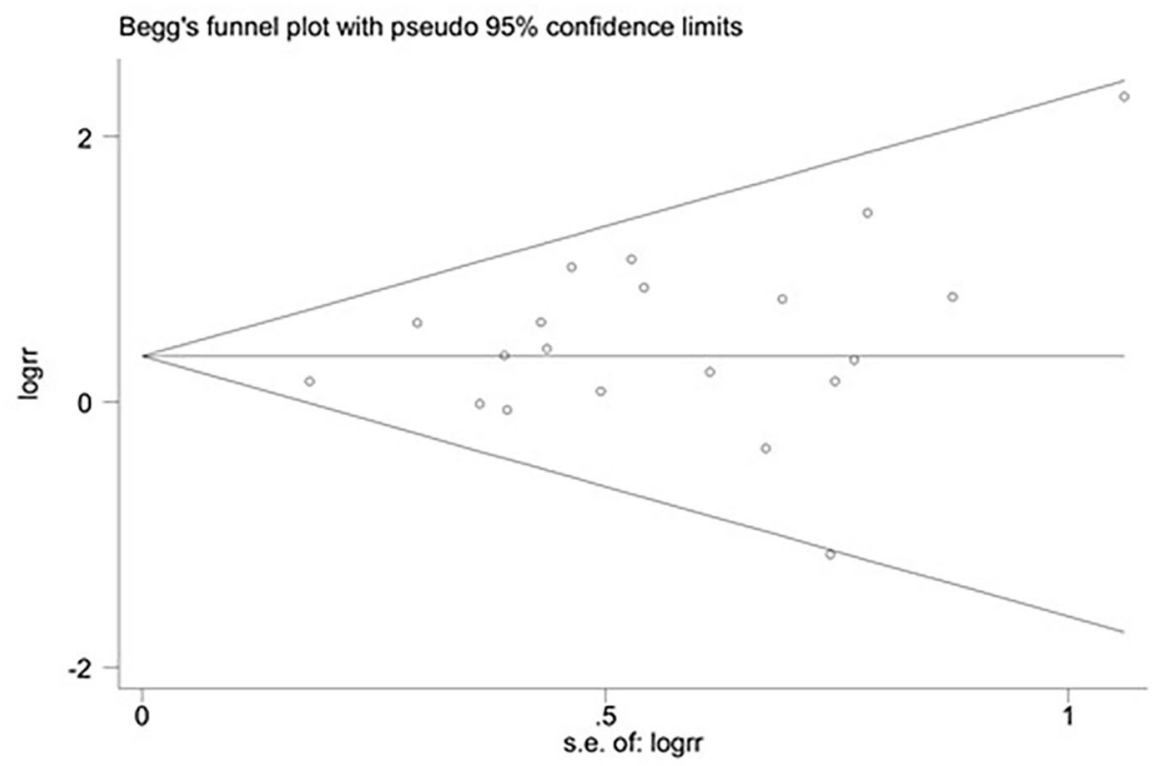

FIGURE 2 | Publication bias: Begg's (A) $(p>0.05)$ and Egger's (B) $(p>0.05)$ funnel plots for possible publication bias in the current study. No publication bias was found, indicating credible results.

\section{Data Extraction and Quality Assessment}

Information, including the first author, initial symptoms researched, and a sample size of severe and mild groups, was extracted from each study, and a Microsoft Excel database was used to record the details. Two independent reviewers (Xiaobo $\mathrm{He}$ and Xudong Feng) conducted the selection and assessment of article quality. Any disagreement was solved by consulting a professional investigator (Maoming Xiong).

\section{Bias Risk Assessment}

We used MINORS (Table 1) to assess the bias risk of included studies.

\section{Data Analysis}

We performed statistical analysis with REVMAN (Review Manager version 5.3, The Nordic Cochrane Center, The Cochrane Collaboration, Copenhagen, 2014). Crude odds ratios (ORs) and $95 \%$ confidence intervals (CIs) were used to estimate 
TABLE 2 | Clinical characteristics of the include studies on COVID-19.

\begin{tabular}{|c|c|c|c|c|c|c|c|c|c|c|c|c|c|c|c|c|c|c|c|c|c|c|c|c|c|c|}
\hline \multirow[t]{2}{*}{ Study } & \multicolumn{2}{|c|}{$\begin{array}{l}\text { Abdominal } \\
\text { pain }\end{array}$} & \multicolumn{2}{|c|}{ Anorexia } & \multicolumn{2}{|c|}{$\begin{array}{l}\text { Chest } \\
\text { tightness }\end{array}$} & \multicolumn{2}{|c|}{ Cough } & \multicolumn{2}{|c|}{ Diarrhea } & \multicolumn{2}{|c|}{ Dyspnea } & \multicolumn{2}{|c|}{ Expectoration } & \multicolumn{2}{|c|}{ Fatigue } & \multicolumn{2}{|c|}{ Headache } & \multicolumn{2}{|c|}{ Hemoptysis } & \multicolumn{2}{|c|}{ Myalgia } & \multicolumn{2}{|c|}{$\begin{array}{l}\text { Nausea } \\
\text { or } \\
\text { vomiting }\end{array}$} & \multicolumn{2}{|c|}{ Pharyngalgia } \\
\hline & $S / T$ & $\mathrm{~N} / \mathrm{T}$ & $S / T$ & $N / T$ & $S / T$ & $N / T$ & $\mathrm{~S} / \mathrm{T}$ & $\mathrm{N} / \mathrm{T}$ & $S / T$ & $N / T$ & $\mathrm{~S} / \mathrm{T}$ & $\mathrm{N} / \mathrm{T}$ & $S / T$ & $N / T$ & $S / T$ & $N / T$ & $S / T$ & $N / T$ & $S / T$ & $N / T$ & $\mathrm{~S} / \mathrm{T}$ & $N / T$ & $S / T$ & $N / T$ & $S / T$ & $N / T$ \\
\hline Cai Q. & - & - & - & - & - & - & $27 / 58$ & $78 / 240$ & $4 / 58$ & $5 / 240$ & & - & - & - & $3 / 58$ & $10 / 240$ & $0 / 58$ & $5 / 240$ & - & - & - & - & - & - & $0 / 58$ & $2 / 240$ \\
\hline Dong L. & - & - & - & - & - & - & $7 / 14$ & $20 / 45$ & - & - & - & - & $2 / 14$ & $10 / 45$ & $6 / 14$ & $2 / 45$ & $2 / 14$ & $3 / 45$ & - & - & $4 / 14$ & $4 / 45$ & - & - & $2 / 14$ & $3 / 45$ \\
\hline Fang $X$. & - & - & - & - & - & - & $14 / 24$ & $31 / 55$ & $3 / 24$ & $1 / 55$ & $4 / 24$ & $5 / 55$ & $3 / 24$ & $7 / 55$ & - & - & - & - & - & - & - & - & - & - & $2 / 24$ & $1 / 55$ \\
\hline Guan W. & - & - & - & - & - & - & $\begin{array}{l}122 / \\
173\end{array}$ & $\begin{array}{l}623 / \\
926\end{array}$ & $\begin{array}{l}10 / \\
173\end{array}$ & $\begin{array}{l}32 / \\
926\end{array}$ & $\begin{array}{l}65 / \\
173\end{array}$ & $\begin{array}{l}140 / \\
926\end{array}$ & $\begin{array}{l}61 / \\
173\end{array}$ & $\begin{array}{l}309 / \\
926\end{array}$ & $\begin{array}{l}69 / \\
173\end{array}$ & $\begin{array}{l}350 / \\
926\end{array}$ & $\begin{array}{l}26 / \\
173\end{array}$ & $\begin{array}{l}124 / \\
926\end{array}$ & $\begin{array}{c}4 / \\
173\end{array}$ & $\begin{array}{c}6 / \\
926\end{array}$ & $\begin{array}{l}30 / \\
173\end{array}$ & $\begin{array}{l}134 / \\
926\end{array}$ & $\begin{array}{l}12 / \\
173\end{array}$ & $\begin{array}{l}43 / \\
926\end{array}$ & $\begin{array}{l}23 / \\
173\end{array}$ & $\begin{array}{l}130 / \\
926\end{array}$ \\
\hline $\begin{array}{l}\text { Huang } \\
\text { C. }\end{array}$ & - & - & - & - & - & - & $11 / 13$ & $20 / 28$ & $0 / 13$ & $1 / 25$ & $12 / 13$ & $10 / 27$ & $5 / 13$ & $6 / 26$ & - & - & $0 / 13$ & $3 / 25$ & $1 / 13$ & $1 / 26$ & - & - & - & - & - & - \\
\hline LiD. & - & - & - & - & - & - & $14 / 17$ & $43 / 63$ & $4 / 17$ & $9 / 63$ & $15 / 17$ & $4 / 63$ & $14 / 17$ & $43 / 63$ & $10 / 17$ & $24 / 63$ & $3 / 17$ & $9 / 63$ & - & - & $3 / 17$ & $19 / 63$ & - & - & - & - \\
\hline LiK. & - & - & - & - & - & - & $24 / 25$ & $41 / 58$ & - & - & $7 / 25$ & 2/58 & $9 / 25$ & $6 / 58$ & - & - & $3 / 25$ & $6 / 58$ & - & - & $5 / 25$ & $10 / 58$ & - & - & $2 / 25$ & $4 / 58$ \\
\hline LiY. & - & - & - & - & - & - & $18 / 27$ & $19 / 22$ & $27 / 27$ & $4 / 22$ & - & - & - & - & $24 / 27$ & $8 / 22$ & - & - & - & - & - & - & - & - & - & - \\
\hline Liu K. & - & - & - & - & - & - & $18 / 21$ & $36 / 43$ & - & - & - & - & $14 / 21$ & $22 / 43$ & $17 / 21$ & $31 / 43$ & - & - & - & - & - & - & - & - & - & - \\
\hline Liu W. & - & - & - & - & - & - & $4 / 11$ & $30 / 67$ & - & - & $6 / 11$ & $14 / 67$ & - & - & - & - & - & - & - & - & - & - & - & - & - & - \\
\hline LuZ. & - & - & - & - & - & - & $16 / 34$ & 22/67 & - & - & - & - & $7 / 34$ & 20/67 & - & - & $2 / 34$ & $7 / 67$ & - & - & - & - & - & - & - & - \\
\hline Wan Q. & - & - & - & - & - & - & $16 / 21$ & $76 / 132$ & - & - & $8 / 21$ & $23 / 132$ & $13 / 21$ & $39 / 132$ & $12 / 21$ & $25 / 132$ & - & - & - & - & $9 / 21$ & $9 / 132$ & - & - & - & - \\
\hline Wan S. & - & - & - & - & $3 / 40$ & 9/95 & $35 / 40$ & $67 / 96$ & $13 / 40$ & $5 / 95$ & $18 / 40$ & 0/95 & $7 / 40$ & $5 / 95$ & - & - & $11 / 40$ & $23 / 95$ & $3 / 40$ & $1 / 95$ & - & - & - & - & $0 / 40$ & 24/95 \\
\hline Wang D. & $3 / 36$ & 0/102 & $24 / 36$ & $31 / 102$ & $2-$ & - & $21 / 36$ & $61 / 102$ & $6 / 36$ & 8/102 & $23 / 36$ & $20 / 102$ & $8 / 36$ & 29/102 & $29 / 36$ & $67 / 102$ & $3 / 36$ & 6/102 & - & - & $12 / 36$ & $36 / 102$ & $4 / 36$ & $10 / 102$ & $12 / 36$ & $12 / 102$ \\
\hline Wu C. & - & - & - & - & - & - & $68 / 84$ & $95 / 117$ & - & - & $50 / 84$ & $30 / 117$ & - & - & - & - & - & - & - & - & - & - & - & - & - & - \\
\hline Xiang T. & - & - & - & - & $0 / 9$ & $4 / 40$ & $6 / 9$ & $13 / 40$ & $0 / 9$ & $2 / 40$ & - & - & $4 / 9$ & $3 / 40$ & $3 / 9$ & $6 / 40$ & - & - & - & - & - & - & - & - & $0 / 9$ & $7 / 40$ \\
\hline Yuan J. & - & - & $8 / 57$ & $9 / 82$ & - & - & $18 / 31$ & $95 / 192$ & $0 / 31$ & $12 / 192$ & 15/31 & 0/192 & $7 / 31$ & 20/192 & - & - & $1 / 31$ & $10 / 192$ & - & - & - & - & - & - & - & - \\
\hline Zhang J. & $6 / 57$ & 2/82 & - & - & - & - & $45 / 53$ & $45 / 67$ & $9 / 57$ & $9 / 82$ & $24 / 53$ & $20 / 67$ & - & - & $39 / 53$ & $51 / 67$ & - & - & - & - & - & - & $5 / 57$ & $19 / 82$ & - & - \\
\hline $\begin{array}{l}\text { Zhang } \\
\text { W. }\end{array}$ & $3 / 9$ & $3 / 56$ & $0 / 9$ & $1 / 56$ & - & - & $3 / 9$ & $15 / 56$ & $3 / 9$ & $3 / 56$ & - & - & $1 / 9$ & $5 / 56$ & 0/9 & $8 / 56$ & $0 / 9$ & 2/56 & - & - & - & - & 0/9 & $1 / 56$ & 0/9 & $3 / 56$ \\
\hline Zheng F. & - & - & - & - & - & - & $21 / 30$ & $80 / 131$ & $1 / 30$ & $16 / 131$ & | 9/30 & $14 / 131$ & - & - & $15 / 30$ & $49 / 131$ & $4 / 30$ & $8 / 131$ & - & - & $4 / 30$ & $14 / 131$ & $0 / 30$ & $6 / 131$ & - & - \\
\hline
\end{tabular}

$S / T$, severe cases/total cases; $N / T$, non-severe cases/total cases. 
TABLE 3 | Meta-analysis outcomes of clinical features.

\begin{tabular}{|c|c|c|c|c|c|c|}
\hline \multirow[t]{2}{*}{ Clinical features } & \multirow[t]{2}{*}{ Number of studies } & \multirow[t]{2}{*}{ Number of patients } & \multicolumn{2}{|c|}{ Heterogeneity } & \multirow[t]{2}{*}{ OR (95\%Cl) } & \multirow[t]{2}{*}{$P$-value } \\
\hline & & & $I^{2}(\%)$ & $p$-value & & \\
\hline Abdominal pain & 3 & 342 & 0 & 0.67 & $7.5(2.4,23.4)$ & 0.0005 \\
\hline Anorexia & 3 & 342 & 43 & 0.17 & $2.8(1.5,5.1)$ & 0.0009 \\
\hline Chest tightness & 2 & 184 & 0 & 0.72 & $0.7(0.2,2.4)$ & 0.55 \\
\hline Cough & 20 & 3,267 & 8 & 0.36 & $1.4(1.2,1.7)$ & 0.0002 \\
\hline Diarrhea & 13 & 2,552 & 56 & 0.007 & $2.3(1.3,4.9)$ & 0.005 \\
\hline Dyspnea & 13 & 2,590 & 72 & $<0.00001$ & $6.2(3.6,10.6)$ & $<0.00001$ \\
\hline Expectoration & 14 & 2,367 & 51 & 0.01 & $1.7(1.2,2.6)$ & 0.009 \\
\hline Fatigue & 13 & 2,436 & 62 & 0.002 & $2.1(1.3,3.3)$ & 0.002 \\
\hline Fever & - & - & 45 & 0.02 & $1.5(1.2,1.9)$ & 0.0005 \\
\hline Headache & 12 & 2,480 & 0 & 0.94 & $1.1(0.8,1.6)$ & 0.48 \\
\hline Hemoptysis & 3 & 1,273 & 0 & 0.77 & $4.0(1.5,11.3)$ & 0.008 \\
\hline Myalgia & 8 & 1,773 & 67 & 0.006 & $1.6(0.8,3.1)$ & 0.15 \\
\hline Nausea or vomiting & 5 & 1,602 & 44 & 0.9 & $0.9(0.6,1.5)$ & 0.66 \\
\hline Pharyngalgia & 9 & 2,005 & 54 & 0.03 & $1.2(0.5,2.7)$ & 0.69 \\
\hline
\end{tabular}

the strength of the association between clinical features and COVID-19 ( $p<0.05$ was considered statistically significant). The $I^{2}$ index, which indicates the percentage of the total variation across studies, was used to assess statistical heterogeneity (14). When $I^{2}<50 \%$, a fixed-effects model was used to determine OR, while when $I^{2}>50 \%$, a random-effects model was selected. We used Begg's rank correlation test and Egger's weighted regression method to assess potential publication bias, with $p<0.05$ indicating statistically significant publication bias (15).

\section{RESULTS}

\section{Study Characteristics}

According to our research method, we collected 142 studies from four databases (PubMed, EMBASE, Web of Science, and $\mathrm{CNKI}$ ). Figure 1 shows the flow chart of selection, and no publication bias existed (Figure 2). Details were as follows: 98 articles were further browsed after duplicates were removed. Of these studies, those which were reviews, case reports, or metaanalyses (17 articles); related to other diseases (13 articles); or not about humans (18 articles) were excluded. Then we conducted a qualification assessment of the remaining 50 articles. Twenty-two articles were excluded for not using IHC as an evaluation method, and eight articles were excluded for lacking relevant data. Finally, 20 studies were analyzed. We extracted and analyzed 14 symptoms (including fever, cough, dyspnea, expectoration, hemoptysis, abdominal pain, diarrhea, chest tightness, headache, myalgia, nausea or vomiting, pharyngalgia, anorexia, and fatigue) with REVMAN. For research purposes, we divided all the initial symptoms into four types: fever, respiratory symptoms (including cough, dyspnea, expectoration, hemoptysis, chest tightness, and pharyngalgia), digestive symptoms (including abdominal pain, diarrhea, and nausea or vomiting), and neurological symptoms (including anorexia, fatigue, myalgia, and headache). Details of patients' clinical features and metaanalysis outcomes are shown in Tables 2, 3, respectively. The initial symptoms we studied in this research are shown in Figure 3, and the indexes marked with a symbol $(\sqrt{ })$ are statistically significant.

\section{Associations Between Fever and Severe Cases}

As shown in Figure 4, meta-analysis results revealed that fever $(\mathrm{OR}=1.5,95 \% \mathrm{CI}: 1.2-1.9 ; p<0.001)$ frequently occurred in patients with severe COVID-19 pneumonia compared with the mild cases.

\section{Associations Between Respiratory Symptoms and Severe Cases}

As shown in Figures 5, 6, meta-analysis results revealed that initial respiratory symptoms including cough $(\mathrm{OR}=1.4,95 \%$ CI: $1.2-1.7 ; p<0.001)$, dyspnea (OR $=6.2$, 95\% CI: 3.610.6; $p<0.001$ ), expectoration ( $\mathrm{OR}=1.7,95 \% \mathrm{CI}: 1.2-2.6$; $p<0.01$ ), and hemoptysis ( $\mathrm{OR}=4.0,95 \% \mathrm{CI}: 1.5-11.3$; $p<$ 0.001 ) occurred frequently in patients with severe COVID-19 pneumonia compared with the mild cases, while chest tightness $(\mathrm{OR}=0.7,95 \% \mathrm{CI}: 0.2-2.4 ; p>0.05)$ and pharyngalgia $(\mathrm{OR}=$ 1.2, 95\% CI: $0.5-2.7 ; p>0.05)$ did not show this characteristic.

\section{Associations Between Digestive Symptoms and Severe Cases}

As shown in Figure 7, meta-analysis results revealed that initial digestive symptoms including abdominal pain ( $\mathrm{OR}=7.5,95 \%$ confidence interval $[\mathrm{CI}]: 2.4-23.4 ; p<0.001)$ and diarrhea (OR 


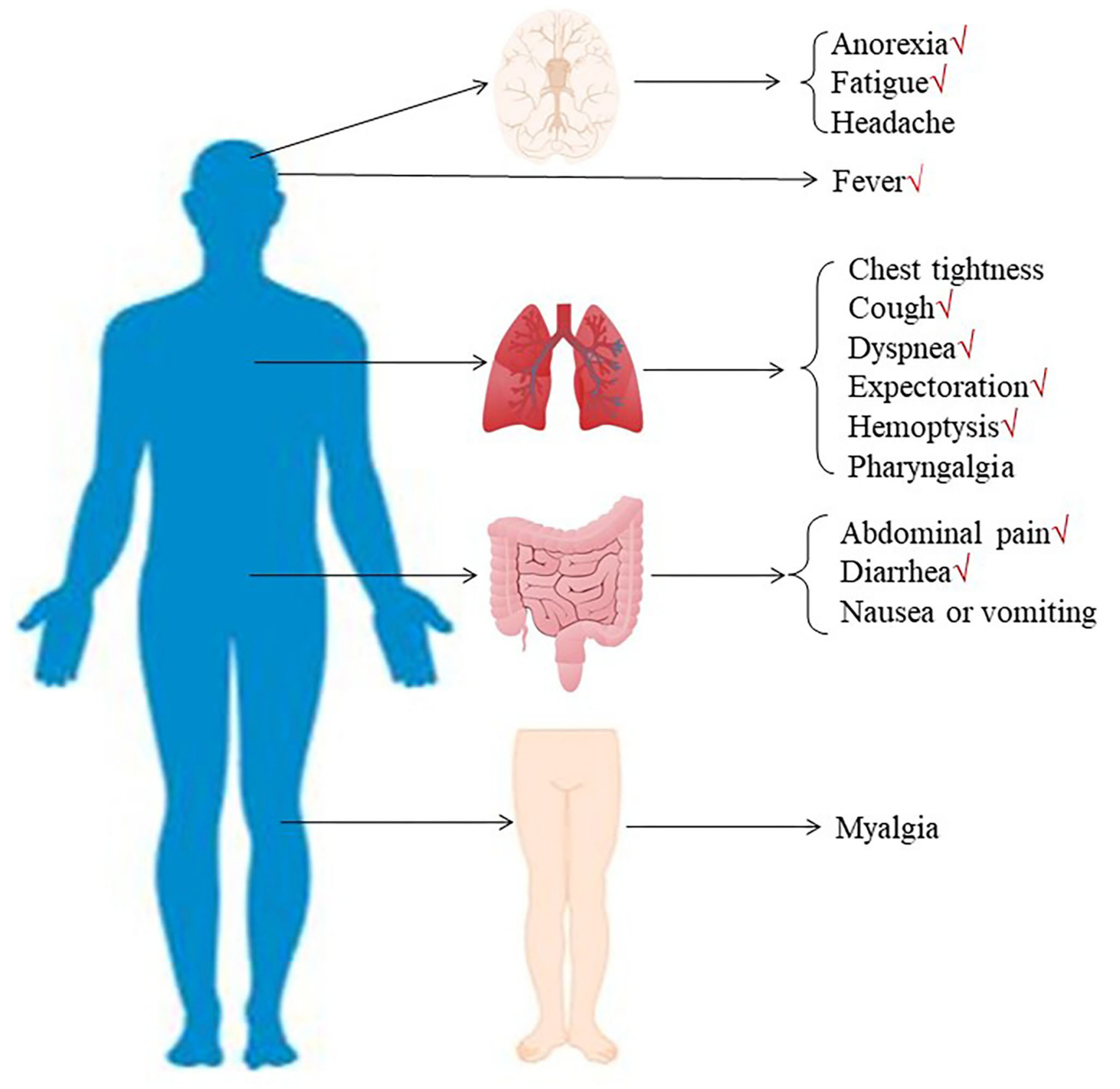

FIGURE 3 | The initial symptoms were divided into three types: respiratory symptoms (including fever, cough, dyspnea, expectoration, hemoptysis, chest tightness, and pharyngalgia), digestive symptoms (including abdominal pain, diarrhea, and nausea or vomiting), and neurological symptoms (including anorexia, fatigue, myalgia, and headache).

$=2.6,95 \%$ CI: $1.3-4.9 ; p<0.001)$ occurred frequently in patients with severe COVID-19 pneumonia compared with the mild cases, while nausea or vomiting $(\mathrm{OR}=0.9,95 \% \mathrm{CI}: 0.6-1.5 ; p$ $>0.05)$ did not show this characteristic.

\section{Associations Between Neurological Symptoms and Severe Cases}

As shown in Figure 8, meta-analysis results revealed that initial neurological symptoms including anorexia $(\mathrm{OR}=2.8,95 \% \mathrm{CI}$ :
$1.5-5.1 ; p<0.001)$ and fatigue (OR $=2.1,95 \% \mathrm{CI}: 1.3-3.3 ; p$ $<0.01$ ) occurred frequently in patients with severe COVID-19 pneumonia compared with the mild cases, while headache (OR $=1.1,95 \% \mathrm{CI}: 0.8-1.6 ; p>0.05)$ and myalgia $(\mathrm{OR}=1.6,95 \% \mathrm{CI}$ : $0.8-3.1 ; p>0.05)$ did not show this characteristic.

\section{Publication Bias}

We used Begg's rank correlation test and Egger's weighted regression method to assess publication bias statistically. As 


\section{Fever}

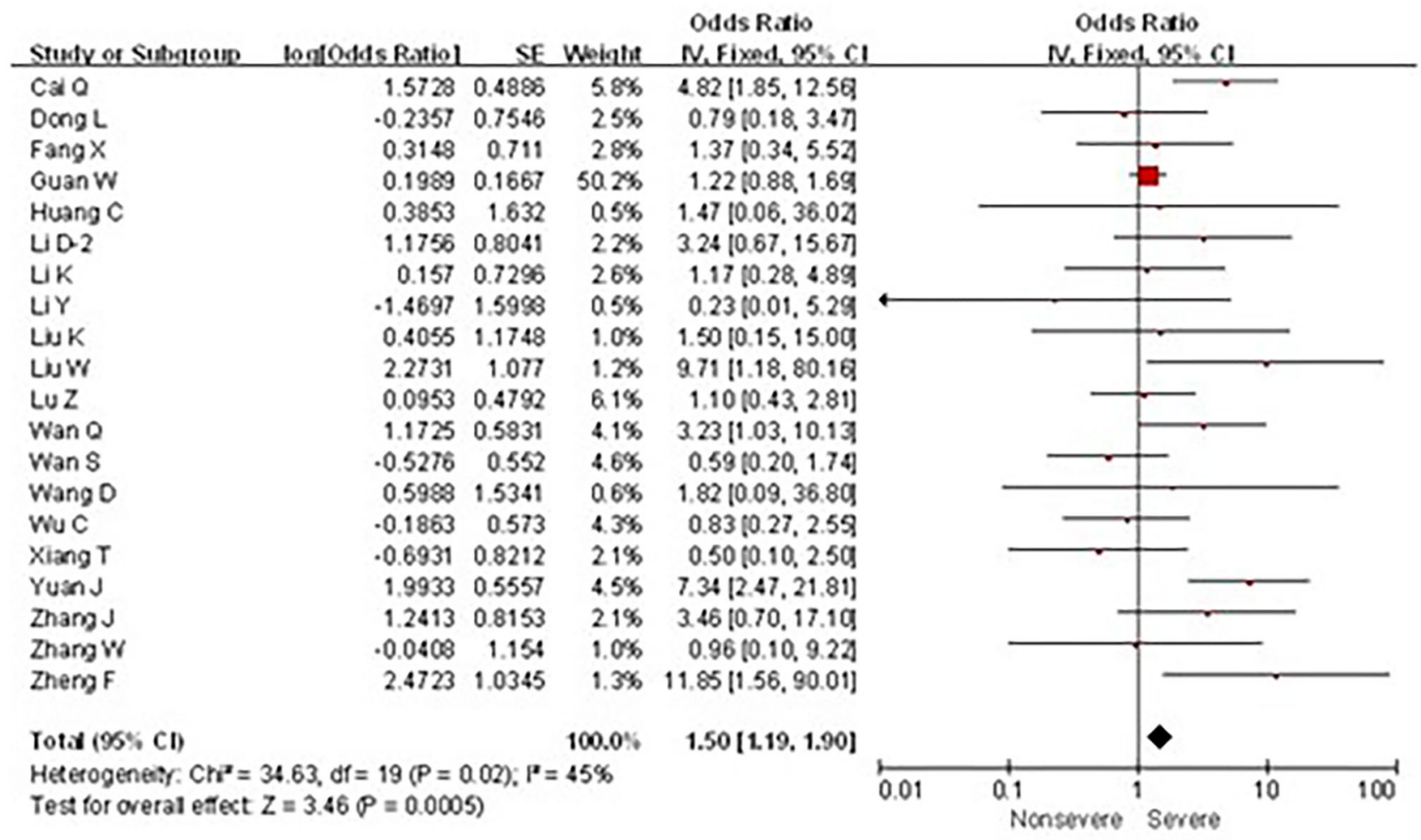

FIGURE 4 | Forest plots of odds ratios (ORs) showed the associations between fever and disease progression of COVID-19 pneumonia.

shown in Figures 2A,B, neither Begg's ( $p=0.453$ ) nor Egger's ( $p=0.246)$ test provided clear evidence of publication bias. These results showed the credibility of the findings reported in this meta-analysis.

\section{DISCUSSION}

Over the past month, nearly one million cases of coronavirus disease 2019 were confirmed in China and other countries in Asia, Africa, Europe, and America. COVID-19 has become an enormous threat to human health around the world and seriously hindered the development of the world economy and the progress of humanity. As a member of the Coronaviridae family, which is distributed widely in humans and other mammals such as bats, masked palm civets, and pangolins $(16,17)$, the novel coronavirus 2019 has a lower mortality but higher morbidity than MERS-CoV and SARS-CoV $(18,19)$. The novel coronavirus 2019 has been designated a Public Health Emergency of International Concern by the WHO because of its high infectivity (20). According to clinical symptoms, laboratory indicators, and imaging findings, COVID-19 is classified as mild, normal, severe, and critical (7). The diagnostic criteria for severe are any of the following: shortness of breath, respiratory rate
$(\mathrm{RR})>30$ times/min; oxygen saturation $<93 \%$ at rest; arterial blood oxygen partial pressure $\left(\mathrm{PaO}_{2}\right)$ /oxygen concentration $\left(\mathrm{FiO}_{2}\right)<300 \mathrm{mmHg}(1 \mathrm{mmHg}=0.133 \mathrm{kPa}$ ) (when the altitude is above $1,000 \mathrm{~m}, \mathrm{PaO}_{2} / \mathrm{FiO}_{2}$ should be corrected according to the following formula: $\mathrm{PaO}_{2} / \mathrm{FiO}_{2} \times$ [atmospheric pressure $(\mathrm{mmHg} / 760])$. Pulmonary imaging showed that the lesions significantly progressed within $24-48 \mathrm{~h}$, and $>50 \%$ were managed according to severity (21). According to the analysis of existing clinical characteristics, severe patients tend to have dyspnea after 1 week in some cases, moderate to low fever, or even no obvious fever. Severe cases were more likely to rapidly develop to ARDS, septic shock, metabolic acidosis, and coagulopathy that are difficult to correct compared with nonsevere patients. Besides, kidney, heart, and other organ damage, and even multiple organ failures were more likely to occur in severe patients $(22,23)$. It is necessary to predict and diagnose severe COVID-19 correctly as early as possible. Especially for countries and regions with poor medical conditions, we can make a preliminary classification of the severity according to the patient's signs, thereby reducing unnecessary medical waste and making the best use of medicines.

According to a statistical description of 656 and 1,994 patients with new coronary pneumonia counted by Alfonso J. RodriguezMorales and Long-Quan Li, the most common clinical symptoms 


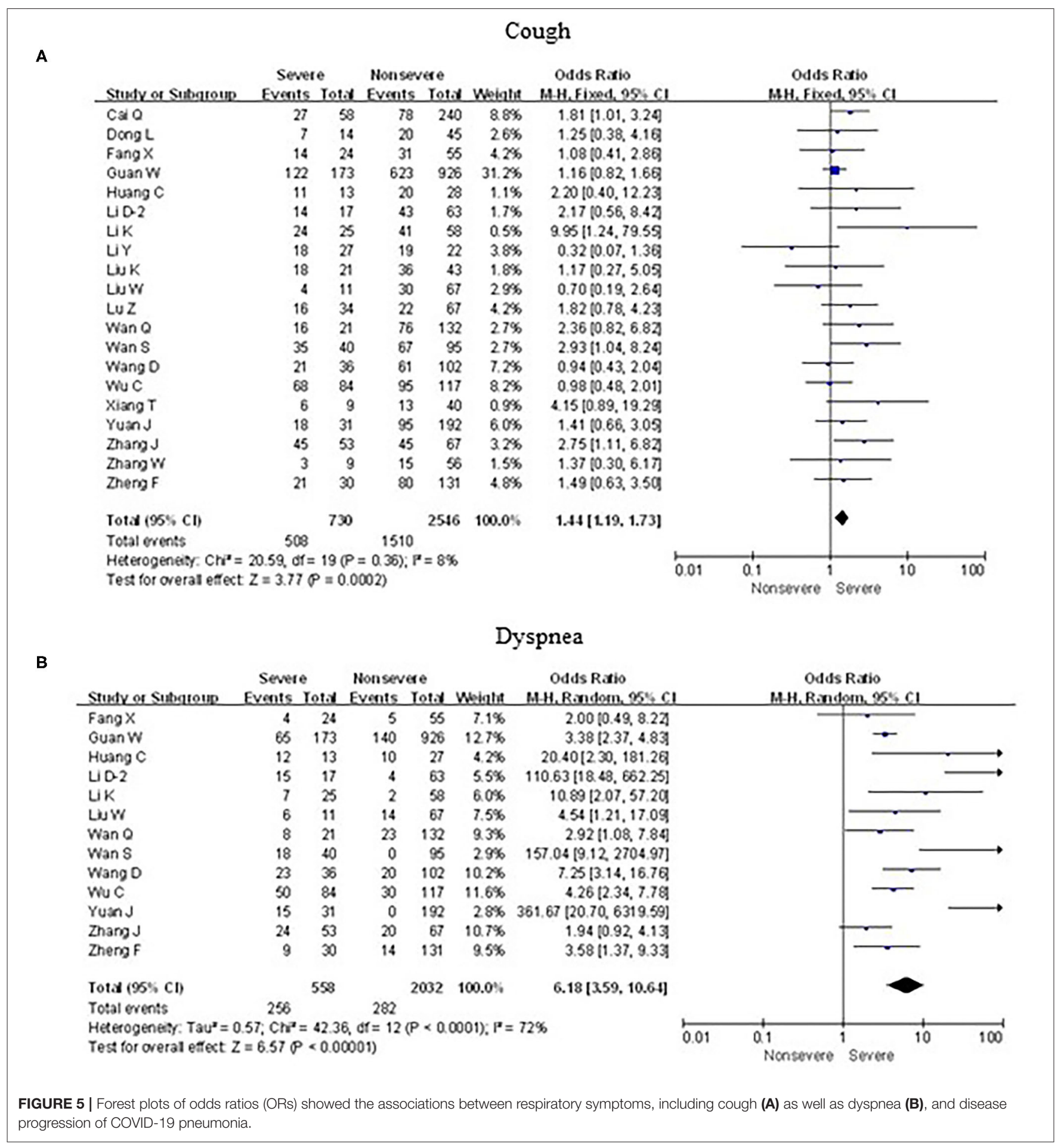

of COVID-19 were fever, cough, and dyspnea (24, 25). Many similar studies have proved this conclusion. However, few studies have discussed how to initially assess the severity of patients with new coronary pneumonia in a short period, to facilitate earlier treatments and reduce complications and mortality. This meta-analysis involved the latest studies from March 2019 to
April 2019 to analyze the clinical characteristics of the novel coronavirus 2019. Our study, which included 3,326 confirmed cases, provided more credible results of clinical features of the novel coronavirus 2019. Although all the studies were case studies, there was no publication bias. In this study, the dominant clinical features of COVID-19 patients were cough 


\section{Expectoration}

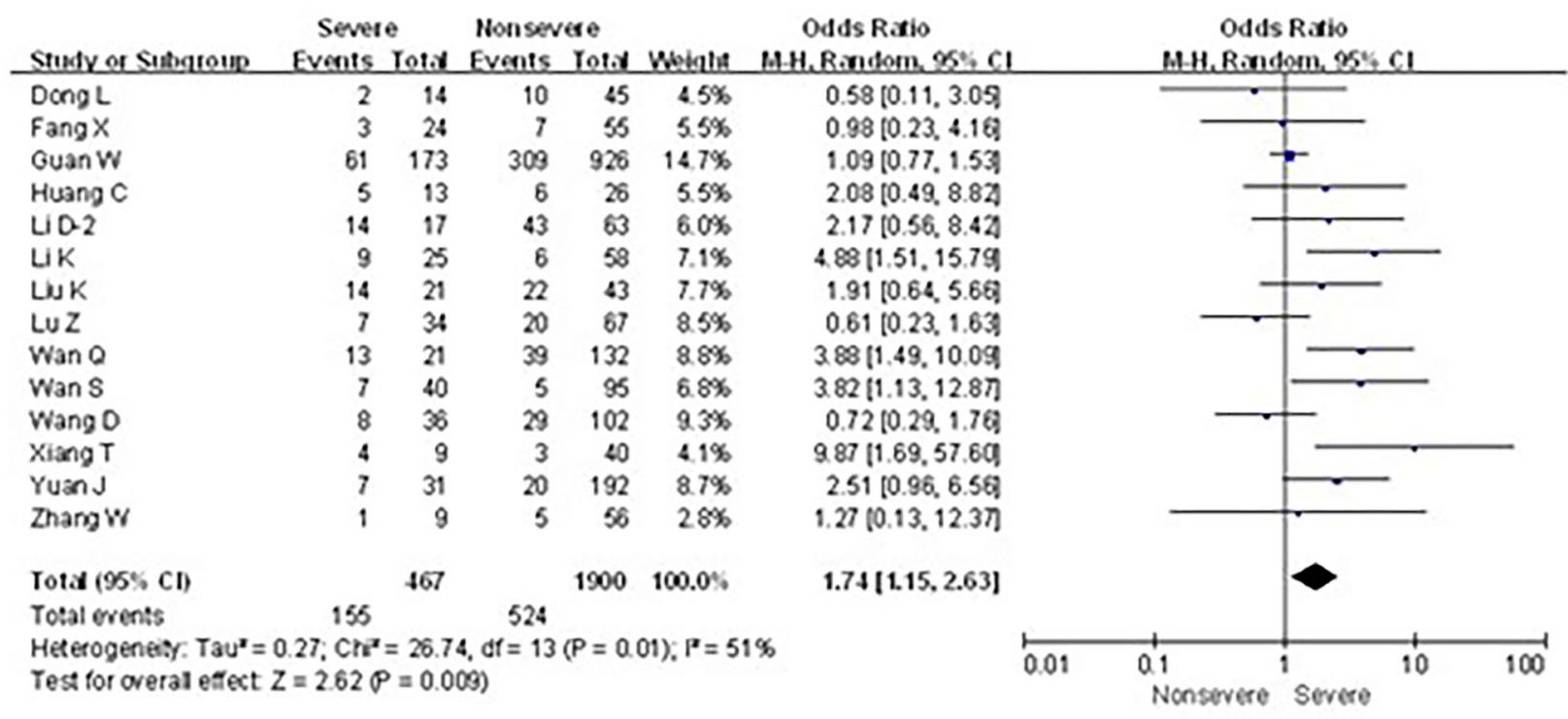

B

\section{Hemoptysis}

\begin{tabular}{|c|c|c|c|c|c|c|c|c|c|c|c|}
\hline Studx of Sutogroup & $\begin{array}{l}\text { Sever } \\
\text { Everits }\end{array}$ & Iotiy & $\begin{array}{l}\text { Nonser } \\
\text { Evants }\end{array}$ & $\begin{array}{l}\text { ere } \\
\text { Yotax }\end{array}$ & Weighte & $\begin{array}{l}\text { Odds Ratio } \\
\text { H. H. Fixed. } 95 \mathrm{cl}\end{array}$ & & $\begin{array}{r}\text { Odds } \\
\text { WH. Fixe }\end{array}$ & $\begin{array}{l}\text { S Ratio } \\
\text { ed. } 25 \mathrm{Cl} 1\end{array}$ & & \\
\hline Guan W & 4 & 173 & 6 & 926 & $61.3 \%$ & $3.63[1.01,13.00]$ & & & & & \\
\hline Huang $\mathrm{C}$ & 1 & 13 & 1 & 26 & $20.5 \%$ & 20810.12 .36 .23 & & & & & \\
\hline Wan $S$ & 3 & 40 & 1 & 95 & $182 \%$ & 7.6210 .77 .75 .63 & & & & & \\
\hline Tota $(95 \% \mathrm{CI})$ & & 226 & & 1047 & $100.0 \%$ & $4.04[1.45,11.27]$ & & & & & \\
\hline Total erents & 8 & & 8 & & & & & & & & \\
\hline $\begin{array}{l}\text { Heterogeneit: } \mathrm{Ch}^{\mathbf{2}}= \\
\text { Test for overal effect }\end{array}$ & $\begin{array}{l}53 . d f=2 \\
=2.67 \%\end{array}$ & $\begin{array}{l}P=0 \\
=0.00\end{array}$ & (8) & & & & 0.01 & $\begin{array}{l}\text { a. } \\
\text { Nonservere }\end{array}$ & 1 Severe & 10 & 100 \\
\hline
\end{tabular}

FIGURE 6 | Forest plots of odds ratios (ORs) showed the associations between respiratory symptoms, including expectoration (A) as well as hemoptysis (B), and disease progression of COVID-19 pneumonia.

(98.5\%) and fever (93.4\%), which were similar to other studies on initial symptoms of COVID-19 patients in China (22, 26, 27). By analyzing the distribution differences of initial symptoms between severe cases and mild cases, we found that some initial symptoms including abdominal pain (OR $=7.5$, 95\% CI: $2.4-$ 23.4), dyspnea ( $\mathrm{OR}=6.2$, 95\% CI: 3.6-10.6), hemoptysis (OR $=4.0,95 \% \mathrm{CI}: 1.5-11.3)$, anorexia $(\mathrm{OR}=2.8,95 \% \mathrm{CI}: 1.5-5.1)$, diarrhea $(\mathrm{OR}=2.6,95 \% \mathrm{CI}: 1.3-4.9)$, fatigue $(\mathrm{OR}=2.1,95 \%$ CI: $1.3-3.3)$, expectoration (OR $=1.7,95 \% \mathrm{CI}: 1.2-2.6)$, fever $(\mathrm{OR}=1.5,95 \% \mathrm{CI}: 1.2-1.9)$, and cough $(\mathrm{OR}=1.4,95 \% \mathrm{CI}$ : $1.2-1.7)$ occurred more frequently in severe COVID-19 patients than in mild COVID-19 patients. However, chest tightness ( $p$ $=0.55)$, headache $(p=0.48)$, myalgia $(p=0.15)$, nausea or vomiting $(p=0.66)$, and pharyngalgia $(p=0.69)$ did not show a significant difference between patients with severe and mild COVID-19. In other words, the symptoms, including abdominal pain, anorexia, diarrhea, dyspnea, expectoration, fatigue, cough, fever, and hemoptysis, had a different distribution in severe cases and mild cases of coronavirus disease 2019, especially abdominal pain, dyspnea, and hemoptysis. The outcomes of our study were of great significance in predicting and diagnosing severe 2019 coronavirus disease, reducing the mortality and preventing its further spread. Some countries with severe epidemics do not have sufficient medical resources such as Italy, Spain, and India. They should pay more attention to the COVID-19 patients whose initial symptoms are abdominal pain, dyspnea, hemoptysis, anorexia, diarrhea, or fatigue because these patients are more likely to deteriorate to a severe type of 2019 coronavirus disease. Moreover, to further reduce the mortality of patients, medical workers should monitor their vital signs closely.

Severe acute respiratory syndrome (SARS) is an infectious disease belonging to the coronavirus family that occurred in 2002 , and it has very similar initial symptoms and complications as the new coronavirus (1). According to research published 


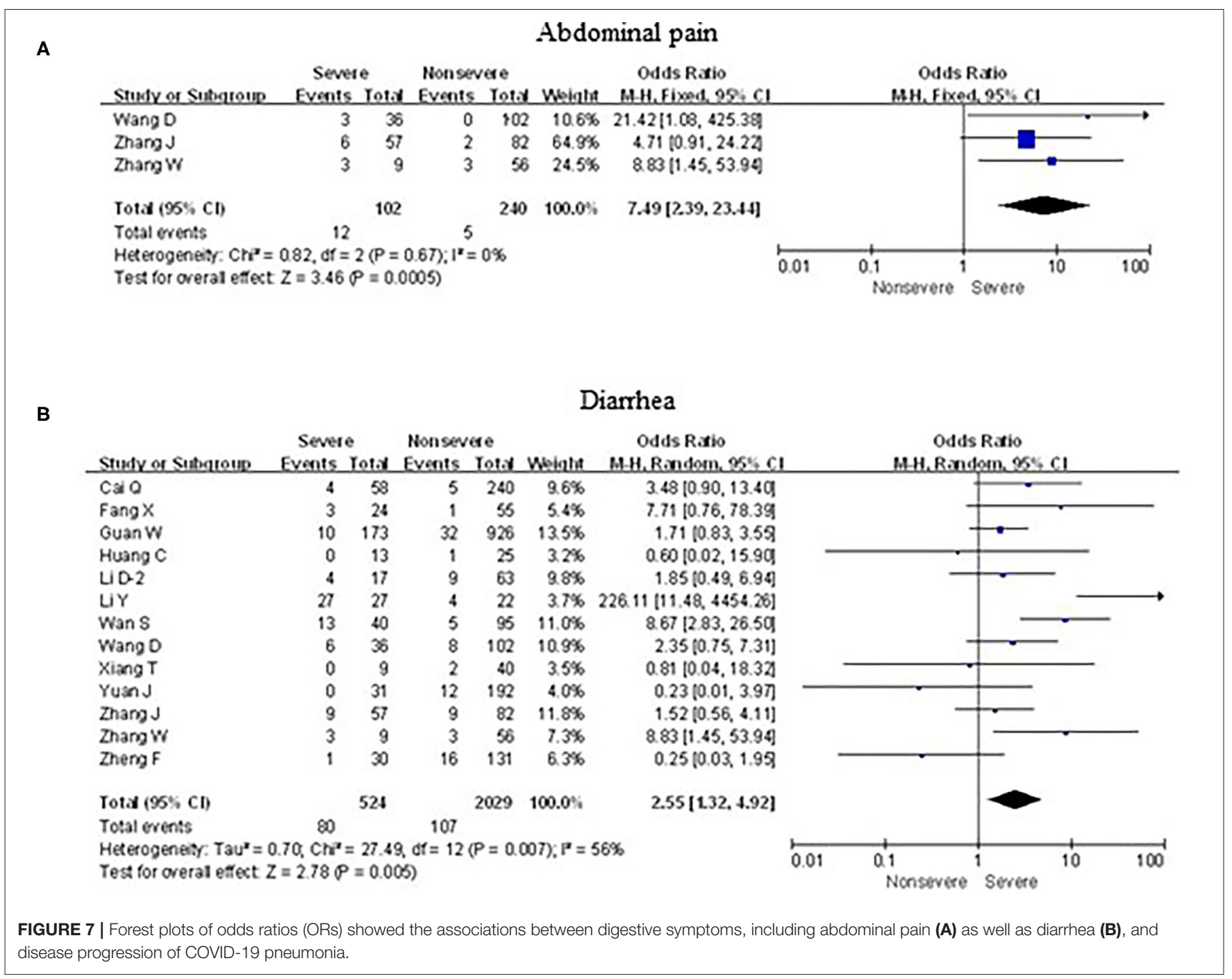

in The Lancet Infectious Diseases in 2004, symptoms such as fever, cough, and respiratory distress could serve as prediction and monitoring indicators for critical SARS (28). The result is consistent with our research. Moreover, Daozheng Huang et al. summarized 4,972 patients with COVID-19 from the end of 2019 to February 12, 2020 (29). They found that some clinical symptoms such as dyspnea, vomiting, and diarrhea had distinct differences between severe and non-severe patients, but no apparent differences were found in the symptoms of headache, fever, myalgia, and arthralgia. Also, calcitonin $\geq 0.05 \mathrm{ng} / \mathrm{mL}$, creatinine $>104 \mu \mathrm{mol} / \mathrm{L}$, lymphocyte count $<1.5 \times 10^{9} / \mathrm{L}$, and bilateral involvement of chest CT were significant risk factors for severe COVID-19. The above findings are highly consistent with our results, while vomiting and fever are contrary to our results. Therefore, it is necessary to expand the sample size of the research subjects for further exploration. What is certain is that when patients show abdominal pain, anorexia, diarrhea, dyspnea, fatigue, cough, or hemoptysis, they are more likely to be diagnosed as severe cases in the later development of the disease.

Our study still has some limitations. First, all the studies included were from China, so it would be better to involve studies in other countries to get a more comprehensive result of COVID19, and the outcomes might be affected by geographical and ethnic differences. Second, more detailed patient information such as laboratory findings and ages were not involved in our meta-analysis for lack of relevant data. Third, some outcomes (including hemoptysis, abdominal pain, and anorexia) were defined with only three studies since many articles have not been published yet, which might increase the risk of bias. Finally, we performed this meta-analysis during the ongoing outbreak of COVID-19, and many regions affected by COVID-19 have not yet presented clinical data, which might skew the results of the analysis.

In conclusion, our study analyzed 3,326 cases and found that some initial symptoms especially abdominal pain, dyspnea, 
A

Anorexia

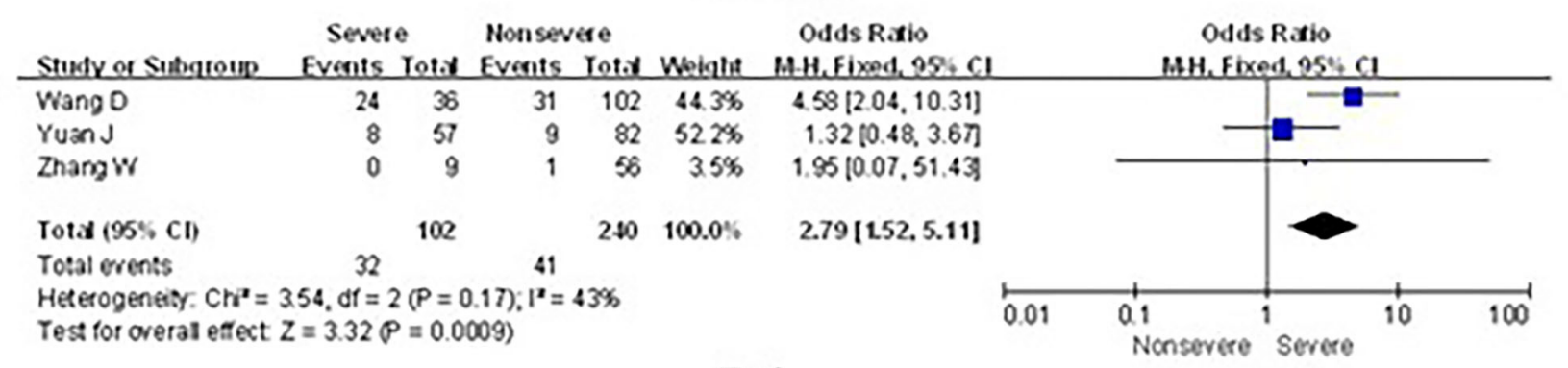

B

\section{Fatigue}

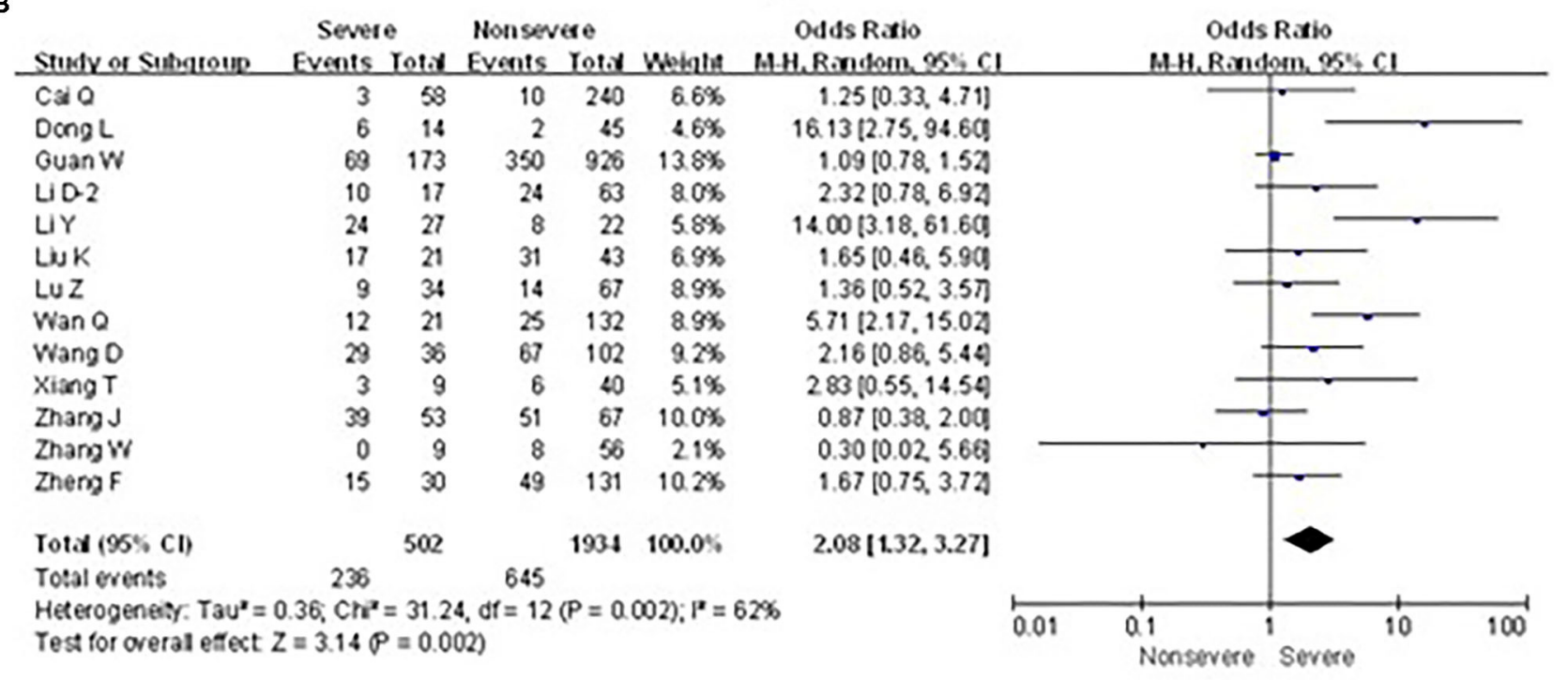

FIGURE 8 | Forest plots of odds ratios (ORs) showed the associations between neurological symptoms, including anorexia (A) as well as fatigue (B), and disease progression of COVID-19 pneumonia.

hemoptysis, anorexia, diarrhea, and fatigue were significantly correlated with a severe type of 2019 coronavirus disease, suggesting that these symptoms could predict severe novel coronary pneumonia. Hospitalized COVID-19 patients with these initial symptoms should be paid more attention to keep a stable vital sign.

\section{DATA AVAILABILITY STATEMENT}

The original contributions presented in the study are included in the article/supplementary materials, further inquiries can be directed to the corresponding author/s.

\section{REFERENCES}

1. Backer JA, Klinkenberg D, Wallinga J. Incubation period of 2019 novel coronavirus (2019-nCoV) infections among travelers from Wuhan, China, 20-28 January 2020. Euro Surveill. (2020) 25:2000062. doi: 10.2807/1560-7917.ES.2020.25.5.20

\section{AUTHOR CONTRIBUTIONS}

$\mathrm{XH}$ : data statistics and analysis. XC: draft writing. XF: literature screening. SC: language modification. HW and MX: paper modification. All authors contributed to the article and approved the submitted version.

\section{FUNDING}

This work was supported by grants from the Key Research and Development Program of Anhui Province (201904a07020045). 
4. Nie X, Fan L, Mu G, Tan Q, Wang M, Xie Y, et al. Epidemiological characteristics and incubation period of 7,015 confirmed cases with Coronavirus Disease 2019 outside Hubei Province in China. J Infect Dis. (2020) 222:26-33. doi: 10.1093/infdis/jiaa211

5. Li L-Q, Huang T, Wang Y-Q, Wang Z-P, Liang Y, Huang T-B, et al. Response to Char's comment: comment on Li et al.: COVID-19 patients' clinical characteristics, discharge rate, and fatality rate of meta-analysis. J Med Virol. (2020) 92:1433. doi: 10.1002/jmv.25924

6. Sokouti M, Sadeghi R, Pashazadeh S, Eslami S, Sokouti M, Ghojazadeh $\mathrm{M}$, et al. Comparative global epidemiological investigation of SARSCoV-2 and SARS-CoV diseases using meta-MUMS tool through incidence, mortality, and recovery rates. Arch Med Res. (2020) 51:458-63. doi: 10.1016/j.arcmed.2020.04.005

7. Kenneson A, Cannon MJ. Review and meta-analysis of the epidemiology of congenital cytomegalovirus (CMV) infection. Rev Med Virol. (2007) 17:25376. doi: 10.1002/rmv.535

8. Gao Y, Li T, Han M, Li X, Wu D, Xu Y, et al. Diagnostic utility of clinical laboratory data determinations for patients with the severe COVID-19. J Med Virol. (2020) 92:791-6. doi: 10.1002/jmv.25770

9. Zhou F, Yu T, Du R, Fan G, Liu Y, Liu Z, et al. Clinical course and risk factors for mortality of adult inpatients with COVID-19 in Wuhan, China: a retrospective cohort study. Lancet. (2020) 395:1054-62. doi: 10.1016/S0140-6736(20)30566-3

10. Guan WJ, Ni ZY, Hu Y, Liang WH, Ou CQ, He JX, et al. Clinical characteristics of coronavirus disease 2019 in China. N Engl J Med. (2020) 382:1708-20. doi: 10.1056/NEJMoa2002032

11. Wan S, Xiang Y, Fang W, Zheng Y, Li B, Hu Y, et al. Clinical features and treatment of COVID-19 patients in northeast Chongqing. J Med Virol. (2020) 92:797-806. doi: 10.1002/jmv.25783

12. Zheng F, Tang W, Li H, Huang YX, Xie YL, Zhou ZG. Clinical characteristics of 161 cases of corona virus disease 2019 (COVID-19) in Changsha. Eur Rev Med Pharmacol Sci. (2020) 24:3404-10. doi: 10.26355/eurrev_202003_ 20711

13. Liu W, Tao ZW, Wang L, Yuan ML, Liu K, Zhou L, et al. Analysis of factors associated with disease outcomes in hospitalized patients with 2019 novel coronavirus disease. Chin Med J (Engl). (2020) 133:1032-8. doi: 10.1097/CM9.0000000000000775

14. Higgins JP, Thompson SG, Deeks JJ, Altman DG. Measuring inconsistency in meta-analyses. BMJ. (2003) 327:557-60. doi: 10.1136/bmj.327.7414.557

15. Egger M, Davey Smith G, Schneider M, Minder C. Bias in metaanalysis detected by a simple, graphical test. BMJ. (1997) 315:629-34. doi: 10.1136/bmj.315.7109.629

16. Coleman CM, Frieman MB. Coronaviruses: important emerging human pathogens. J Virol. (2014) 88:5209-12. doi: 10.1128/JVI.03488-13

17. Cui J, Li F, Shi ZL. Origin and evolution of pathogenic coronaviruses. Nat Rev Microbiol. (2019) 17:181-92. doi: 10.1038/s41579-018-0118-9

18. Ksiazek TG, Erdman D, Goldsmith CS, Zaki SR, Peret T, Emery S, et al. A novel coronavirus associated with severe acute respiratory syndrome. $N$ Engl J Med. (2003) 348:1953-66. doi: 10.1056/NEJMoa030781
19. Kuiken T, Fouchier RA, Schutten M, Rimmelzwaan GF, van Amerongen G, van Riel D, et al. Newly discovered coronavirus as the primary cause of severe acute respiratory syndrome. Lancet. (2003) 362:263-70. doi: 10.1016/S0140-6736(03)13967-0

20. Zheng Z, Peng F, Xu B, Zhao J, Liu H, Peng J, et al. Risk factors of critical \& mortal COVID-19 cases: a systematic literature review and meta-analysis. $J$ Infect. (2020) 81:e16-25. doi: 10.1016/j.jinf.2020.04.021

21. The Diagnosis and Treatment Plan for the Novel Coronavirus Disease. 7th ed. (2020). Available online at: http://www.nhc.gov.cn/yzygj/s7653p/202003/ 46c9294a7dfe4cef80dc7f5912eb1989.shtml (accessed October 15, 2020).

22. Huang C, Wang Y, Li X, Ren L, Zhao J, Hu Y, et al. Clinical features of patients infected with 2019 novel coronavirus in Wuhan, China. Lancet. (2020) 395:497-506. doi: 10.1016/S0140-6736(20)30183-5

23. Wang D, Hu B, Hu C, Zhu F, Liu X, Zhang J, et al. Clinical characteristics of 138 hospitalized patients with 2019 novel coronavirus-infected pneumonia in Wuhan, China. JAMA. (2020) 323:1061-9. doi: 10.1001/jama.2020.1585

24. Rodriguez-Morales AJ, Cardona-Ospina JA, Gutierrez-Ocampo E, VillamizarPena R, Holguin-Rivera Y, Escalera-Antezana JP, et al. Clinical, laboratory and imaging features of COVID-19: a systematic review and meta-analysis. Travel Med Infect Dis. (2020) 34:101623. doi: 10.1016/j.tmaid.2020.101623

25. Li LQ, Huang T, Wang YQ, Wang ZP, Liang Y, Huang TB, et al. COVID19 patients' clinical characteristics, discharge rate, and fatality rate of metaanalysis. J Med Virol. (2020) 92:577-83. doi: 10.1002/jmv.25757

26. Chen N, Zhou M, Dong X, Qu J, Gong F, Han Y, et al. Epidemiological and clinical characteristics of 99 cases of 2019 novel coronavirus pneumonia in Wuhan, China: a descriptive study. Lancet. (2020) 395:507-13. doi: 10.1016/S0140-6736(20)30211-7

27. Li Q, Guan X, Wu P, Wang X, Zhou L, Tong Y, et al. Early transmission dynamics in Wuhan, China, of novel coronavirus-infected pneumonia. N Engl J Med. (2020) 382:1199-207. doi: 10.1056/NEJMoa2001316

28. Ho MS, Su IJ. Preparing to prevent severe acute respiratory syndrome and other respiratory infections. Lancet Infect Dis. (2004) 4:684-9. doi: 10.1016/S1473-3099(04)01174-0

29. Huang D, Lian X, Song F, Ma H, Lian Z, Liang Y, et al. Clinical features of severe patients infected with 2019 novel coronavirus: a systematic review and meta-analysis. Ann Transl Med. (2020) 8:576. doi: 10.21037/atm-20-2 124

Conflict of Interest: The authors declare that the research was conducted in the absence of any commercial or financial relationships that could be construed as a potential conflict of interest.

Copyright (c) $2021 \mathrm{He}$, Cheng, Feng, Wan, Chen and Xiong. This is an open-access article distributed under the terms of the Creative Commons Attribution License (CC $B Y)$. The use, distribution or reproduction in other forums is permitted, provided the original author(s) and the copyright owner(s) are credited and that the original publication in this journal is cited, in accordance with accepted academic practice. No use, distribution or reproduction is permitted which does not comply with these terms. 